\title{
Chromodomain helicase DNA binding protein 5 plays a tumor suppressor role in human breast cancer
}

Xiao $\mathrm{Wu}^{1}$, Zhengmao Zhu ${ }^{1 *}$, Weidong $\mathrm{Li}^{3}$, Xiaoying $\mathrm{Fu}^{2}$, Dan Su${ }^{1}$, Liya Fu', Zhiqian Zhang ${ }^{1}$, Ang Luo', Xiaodong Sun ${ }^{2}, \mathrm{Li} \mathrm{Fu}^{3^{*}}$ and Jin-Tang Dong ${ }^{1,2^{*}}$

\begin{abstract}
Introduction: The chromodomain helicase DNA binding protein 5 (CHD5) has recently been identified as a tumor suppressor in a mouse model. The CHD5 locus at $1 p 36$ is deleted, and its mutation has been detected in breast cancer. We, therefore, evaluated whether CHD5 plays a role in human breast cancer.

Methods: We screened mutations in 55 tumors, determined promoter methylation in 39 tumors, measured RNA expression in 90 tumors, analyzed protein expression in 289 tumors, and correlated expression changes with clinicopathological characteristics of breast cancer. Functional effects of CHD5 on cell proliferation, invasion and tumorigenesis were also tested.
\end{abstract}

Results: Although only one mutation was detected, CHD5 mRNA expression was significantly reduced, accompanied by frequent genomic deletion and promoter methylation, in breast cancer. The extent of methylation was significantly associated with reduced mRNA expression, and demethylating treatment restored CHD5 expression. Lower CHD5 mRNA levels correlated with lymph node metastasis $(P=0.026)$. CHD5 protein expression was also reduced in breast cancer, and lack of CHD5 expression significantly correlated with higher tumor stage, ER/PR-negativity, HER2 positivity, distant metastasis and worse patient survival $(P \leq 0.01)$. Functionally, ectopic expression of CHD5 in breast cancer cells inhibited cell proliferation and invasion in vitro and tumorigenesis in nude mice. Consistent with the inhibition of invasion, CHD5 down-regulated mesenchymal markers vimentin, $\mathrm{N}$-cadherin and ZEB1 in breast cancer cells.

Conclusion: Down-regulation of CHD5, mediated at least in part by promoter methylation, contributes to the development and progression of human breast cancer.

\section{Introduction}

Tumorigenesis is a multi-step process that results from progressive accumulation of genetic and epigenetic alterations in different genes. Chromosomal loss, which leads to the inactivation of tumor suppressor genes, is one of the most common genetic alterations detected in human cancer. Previous publications have documented

\footnotetext{
* Correspondence: zhuzhengmao@nankai.edu.cn; fuli@tijmu.edu.cn; j. dong@emory.edu

'Department of Genetics and Cell Biology, Nankai University College of Life Sciences, 94 Weijin Road, Tianjin 300071, China

${ }^{3}$ Key Laboratory of Breast Cancer Research, Department of Breast Cancer Pathology and Research Laboratory, Cancer Hospital of Tianjin Medical

University, Huan Hu Xi Road, Tianjin 300060, China

Full list of author information is available at the end of the article
}

that the $\mathrm{p} 36$ band of chromosome $1,1 p 36$, is frequently deleted in a wide range of human cancers, including those of epithelial, neural and hematopoietic origin [1]. Recently, Bagchi et al. identified CHD5, which localizes to the deletion region at $1 p 36$, as a tumor suppressor gene through functional analysis in a mouse model. Chd5 knock-down was associated with hyperproliferation and reduced apoptosis and senescence, primarily through the $\mathrm{p} 19^{\mathrm{Arf}} / \mathrm{p} 53$ pathway [2].

CHD5 belongs to the chromodomain helicase DNA binding domain (CHD) family, which is a subclass of the Swi/Snf proteins $[3,4]$. Of nine members of the CHD family (CHD1-CHD9), two (CHD3 and CHD4) are components of the nucleosome remodeling and

\section{Biomed Central}


histone deacetylation (NuRD) complex and play an important role in chromatin remodeling [5,6]. As CHD5 shares the same functional domain with $\mathrm{CHD} 3$ and CHD4, it may also modulate chromatin remodeling and thus affect normal development and cancer.

Evidence that CHD5 functions as a tumor suppressor in human cancer has principally come from studies of neuroblastoma, in which CHD5 mRNA expression was down-regulated likely through promoter methylation in tumors, and high expression of CHD5 was statistically associated with better patient survival [7]. Furthermore, ectopic expression of CHD5 in neuroblastoma cell lines suppressed clonogenicity and tumor growth [6,7]. Hypermethylation of CHD5 promoter has also been detected in gastric, colorectal and ovarian cancers, and somatic mutations have been detected in ovarian cancer [8-11]. However, whereas $1 p 36$ is commonly deleted in human breast cancers, the role of CHD5 in breast cancer has not been evaluated.

We hypothesize that CHD5 is a tumor suppressor gene in breast cancer and tested this hypothesis in this study. We examined CHD5 for somatic mutation, copy number changes, mRNA and protein expression, and promoter methylation in primary tumors and cell lines from human breast cancer. In addition, we assessed its effect on cell proliferation in vitro and in vivo. We found that while CHD5 mutation was relatively rare, it had frequent down-regulation, hemizygous deletion and promoter methylation. Promoter hypermethylation correlated with lower levels of CHD5 mRNA expression, and demethylating treatment decreased promoter methylation and increased CHD5 expression, suggesting that promoter methylation is responsible at least in part for reduced CHD5 expression in breast cancer. Interestingly, reduced CHD5 expression significantly correlated with lymph node metastasis, recurrence and shorter patient survival in breast cancer. In addition, ectopic expression of $\mathrm{CHD} 5$ suppressed cell proliferation and tumor growth of the MDA-MB-231 cell line by arresting cell cycle at the G0/ G1 phase, and inhibited invasiveness of MDA-MB-231 and Hs $578 \mathrm{~T}$ cells in vitro. Our results strongly support a tumor suppressor role for CHD5 in breast cancer.

\section{Materials and methods}

\section{Cell lines and tissues}

In total, 32 breast cancer cell lines (BT-20, BT-474, BT549, BT-483, CAMA-1, DU4475, HCC1143, HCC1395, HCC1500, HCC1599, HCC1806, HCC1937, HCC202, HCC2218, HCC38, HCC70, Hs 578T, MCF7, MDA-MB134, MDA-MB-157, MDA-MB-175, T-47D, MDA-MB231, MDA-MB-361, MDA-MB-415, MDA-MB-453, MDA-MB-468, SW527, UACC893, ZR-75-1, ZR-75-30, BRF-71T) and two immortalized non-neoplastic breast epithelial cell lines (184A1 and BRF-97T) were used in this study. Of these, BRF-97T and BRF-71T were purchased from Biological Research Faculty \& Facility (BRFF, Ijamsville, MD, USA), and the rest were purchased from American Type Culture Collection (Manassas, VA, USA). The primary culture of human mammary epithelial cells (HMEC) was purchased from Cambrex (East Rutherford, NJ, USA). Cells were cultured according to the manufacturers' protocols.

Tumor tissues and adjacent normal tissues were obtained from 377 breast cancer patients who received surgery in the Cancer Hospital of Tianjin Medical University, Tianjin, China. Freshly frozen tissues from 107 patients were used to extract RNA or DNA samples, of which 58 were stored in RNAlater ${ }^{\circledR}$ solution and used for RNA extraction and CHD5 mRNA expression analysis, 30 had bisulfite-treated DNA from a previous study and were used for promoter methylation analysis (19 of them also used for RNA expression analysis), and 38 were used for mutation detection. Formalin-fixed paraffin-embedded primary tumor specimens from 289 patients were prepared in a tissue microarray format and used for CHD5 protein expression analysis by immunohistochemical (IHC) staining, which included 19 tumor specimens that were also used for mRNA expression and promoter methylation analyses. Samples were from the tissue bank at the Cancer Hospital of Tianjin Medical University and were used entirely based on availability. Use of human tissues and clinicopathological information was approved by the Institutional Ethics Committee. Genomic DNA was extracted using the DNeasy Blood \& Tissue kit (Qiagen, Shanghai, China ), and total RNA was isolated using the RNeasy Mini kit (Qiagen).

The numbers of samples for different analyses were different because we used samples from our previous studies and many of them ran out of DNA, RNA or bisulfite-treated DNA. The majority of specimens used for IHC staining did not have DNA or RNA samples available. All samples with a result for any readout were included in this manuscript.

\section{Real-time and semi-quantification PT-PCR}

Reverse transcription reaction was performed using $2 \mu \mathrm{g}$ total RNA with M-MLV reverse transcriptase (Promega, Madison, WI, USA). Real-time PCR reaction was performed in $25 \mu \mathrm{l}$ reaction volume using SYBR Premix Ex Taq kit (TaKaRa, Dalian, China) and carried out on an iQ5 Multicolor Real-Time PCR Detection System (Bio-Rad, Hercules, CA, USA). The CHD5 expression levels were normalized according to GAPDH in each sample. Primers used for $C H D 5$ real time PCR were 5'CAAGTGTAAAGGGAAGCGGAAGAAG-3' (forward) 
and 5'-CTTTTTATTCGGGGAGTAGTCAC-3' (reverse), and those for GAPDH were 5'-GGTGGTCTCCTCTGAC TTCAACA-3' (forward) and 5'-GTTGCTGTAGCCAAATTCGTTGT-3' (reverse). CHD5 mRNA expression reading in HMEC was defined as 1, and CHD5 expression levels for other samples were normalized accordingly. Primer sequences for $C H D 5$ semi-quantification PCR were 5'-TGAAGAAACTGCGGGATG-3' (forward) and 5'TGCCGAACTTGAGGATGT-3' (reverse).

\section{Mutation and methylation analysis}

The 40 coding exons and adjacent splicing junctions of CHD5 were amplified by PCR using previously reported primers and procedures [12]. PCR products were purified and sequenced (Invitrogen, Beijing, China). When a sequence alteration was detected, PCR and sequencing were repeated to confirm it. For confirmed alterations in tumor samples, PCR and sequencing were performed in matched normal samples to determine whether an alteration was somatic or germline.

Promoter methylation analysis was conducted following a published method [13]. Two pairs of primers, 5'TTTAGGGGTTTGTATGGGTTTTAG-3' (F1)/5'-CCC TCTCCAAAAAAAATTAAAAAA-3' (R1) [7] and 5'-T TTTTTTGGAGAGGGGGTTAGG-3' (F2)/5'-CTATAACAACCCCATCCCAT-3' (R2), were used. These primers amplify the $C G$ rich region of the CHD5 promoter from -841 to -246 . Purified PCR products were cloned into pMD18-T vector (TaKaRa, Dalian, China). At least eight clones for each sample were sequenced. Methylation levels for each CpG site were indicated by the ratio of methylation positive clones to the total number of clones sequenced, and were categorized into three groups in cell lines: high (ratio $>0.5)$, low $(0<$ ratio $<0.5)$ and none $($ ratio $=0)$ (marked as dark, gray and white dots, respectively.). The average methylation level at a CpG site was also presented.

\section{Copy number detection}

Copy number changes in the CHD5 gene were detected by real-time PCR using the SYBR Premix Ex Taq kit (TaKaRa). Primer sequences for CHD5 were 5'-CTGTTG CTGCAGTTCCTTCTC-3' and 5'-ATGAAGGACAGAACCTGCCTG-3'. The RNaseP gene, which rarely has copy number changes in tumors [14], was used as an internal control for a stable diploid copy number. Primer sequences for RNaseP were 5'-CCTGGTACATGCCACTGATG-3' and 5'-AGTGTAGAGGGCAAGCCAGA-3'. Briefly, 10 ng genomic DNA from each sample was used as the template for PCR with either CHD5 or RNaseP primers in a volume of $20 \mu \mathrm{l}$. The final concentration for each primer was $0.25 \mu \mathrm{M}$. CHD5 copy number was determined by dividing the $\triangle \mathrm{Ct}$ value for $C H D 5$ by that for RNaseP. For cell lines, the average CHD5/RNaseP ratio among a pool of normal human genomic DNA (HGD) was defined as 1 and used as the value for a normal genome, and a deletion was defined by a ratio that was 0.5 or less. For primary tumors, a deletion was defined when the CHD5/RNaseP ratio in a tumor was about half or less of that in its matched non-cancerous tissue.

\section{Western blotting}

Western blotting was performed according to a published protocol [15]. Antibodies for the following proteins were used: CHD5 (rabbit polyclonal, 1:1,000 dilution, Strategic Diagnostics, Newark, DE, USA), $\beta$-actin (A1978, SigmaAldrich, Beijing, China), p21 (\#610233, BD Biosciences, Franklin Lakes, NJ, USA), p53 (sc-47698, Santa Cruz Biotechnology, Santa Cruz, CA, USA), vimentin (\#3932, Cell Signaling Technology, Beverly, MA, USA), N-cadherin (\#610920, BD Biosciences), E-cadherin (\#3195, Cell Signaling) and ZEB1 (sc-25388, Santa Cruz Biotechnology).

\section{Immunohistochemical (IHC) staining}

Immunohistochemical analysis was performed as previously described [16], using polyclonal rabbit anti-CHD5 antibody (1:2,000 dilution). The pre-immune serum was used as the negative control. In evaluating the specificity of the CHD5 antibody, we made cell pellets of ZR-75-1 (CHD5-negative) and T-47D (CHD5-positive) cells in agarose, fixed them in formalin, embedded in paraffin, prepared sections, and then conducted IHC staining. Detection of strong signals in T-47D but no signals in ZR-75-1 cells validated the antibody for IHC staining.

Protein expression levels of CHD5 were calculated by multiplying the intensity of nucleus staining ( $0=$ no staining, 1 = low intensity, 2 = medium intensity, and 3 = high intensity) with the percentage of positively stained cells ( $0=$ no, $1=1$ to $25 \%, 2=26$ to $50 \%, 3=51$ to $100 \%)$. A combined index (intensity score $\times$ percentage score) of 0 or 1 was considered as negative staining (-), while an index of 2 or 3 as weak staining (+), 4 to 6 as moderate staining $(++)$, and 9 as strong staining $(+++)$. In statistical analysis, CHD5 expression levels were categorized into two groups: lack of expression (-) and weak to strong expression $(+,++$, and +++$)$.

\section{Colony formation assay}

The CHD5 expression plasmid was constructed by cloning the coding region of CHD5 into the pcDNA3.0 vector (Invitrogen). MDA-MB-231 cells were seeded in 6 -well plates at a density of $5 \times 10^{5}$ cells per well and transfected by using the lipofectamine 2000 reagent (Invitrogen, Beijing, China). Forty-eight hours after transfection, one well of cells was harvested to confirm CHD5 expression, and the remaining wells were cultured in selection medium containing $800 \mu \mathrm{g} / \mathrm{ml} \mathrm{G418}$ (Sigma) for two weeks. Cells were then fixed, stained 
with sulforhodamine B (SRB), and measured for optical intensities, which indicated cell numbers, as described in our previous publication [17].

\section{RNA interfering}

Small-interfering RNAs (siRNAs) for the CHD5 gene were purchased from Qiagen and Invitrogen. Two of them, named Q7 (Qiagen) and I20 (Invitrogen), were confirmed to be capable of knocking down CHD5 and thus were used. The target sequence of Q7 was 5'-ACGGTACATGATCCTCAACGA-3' and that of I20 was 5'-CAGCAGTTCTGCTTCCTCCTCTCAA-3'. A siRNA that does not target any known genes was purchased from Rui Bo (Guangzhou, China) and used as a control. The Lipofectamine RNAiMAX transfection reagent (Invitrogen) was used to transfect siRNAs into cells following the manufacturer's instruction.

\section{Flow cytometric cell cycle analysis}

MDA-MB-231 cells transfected with pcDNA3.0 vector or CHD5 expression plasmid were selected using G418 (800 $\mu \mathrm{g} / \mathrm{ml}$; Sigma) for two weeks. $1 \times 10^{6}$ cells of each group were collected, fixed with $70 \%$ ethanol for 24 hours, washed and re-suspended with phosphate-buffered saline (PBS), incubated with propidium iodide $(20 \mathrm{mg} / \mathrm{ml}$, Sigma) and Rnase A $(20 \mathrm{mg} / \mathrm{ml})$ for $30 \mathrm{~min}$ in the dark, and analyzed on a BD FACSCalibur flow cytometer (Franklin Lakes, NJ, USA).

\section{Cell proliferation analysis}

After transfection and selection with G418 for two weeks, MDA-MB-231 cells were harvested, diluted into five cells/ $\mathrm{ml}$ using selection medium, plated into 96-well plates at $100 \mu \mathrm{l}$ per well, and cultured for another two to three weeks. Cells surviving in a well were propagated and confirmed for CHD5 expression. Parental or clones of transfected cells were plated into 12 -well plates at $3 \times 10^{4}$ cells/ well, cultured for different times, fixed, stained with SRB and measured for cell numbers.

Hs $578 \mathrm{~T}$ cells were also transfected with CHD5-expressing plasmid or control plasmids using lipofectamine 2000 reagent. After selection using G418 $(400 \mu \mathrm{g} / \mathrm{ml})$ for two weeks, the population cells of each group were plated into 12-well plates and used for cell proliferation analysis.

\section{Tumor growth assay}

One $\times 10^{6}$ parental or clones of transfected MDA-MB231cells were mixed with Matrigel (BD Biosciences, San Jose, CA, USA) and injected subcutaneously into four weeks old female BALB/c nude mice (eight mice for each group). Tumor volumes were measured once a week and calculated as below: $\mathrm{L} \times \mathrm{W}^{2} \times 0.523 \mathrm{~mm}^{3}$, where $\mathrm{L}$ and $\mathrm{W}$ indicate the length and the width of a tumor. Mice were sacrificed at five weeks after injection, and tumors were surgically removed, weighed, and fixed in $4 \%$ formalin. Hematoxylin and eosin staining was performed for histological examination. The animal experiment was approved by the animal care and use center of Nankai University, Tianjin, China.

\section{Invasion assay}

The Boyden chamber assay was used for invasion assay. Briefly, $1 \times 10^{5}$ cells suspended in $200 \mu \mathrm{l}$ serum-free medium were plated into the top chamber with $50 \mu \mathrm{l}$ Matrigel-coated membrane ( $8 \mu \mathrm{M}$ pole size, BD Biosciences, Shanghai, China). The chambers were then placed into 24-well plates with $600 \mu \mathrm{l}$ serum-containing $(10 \%)$ medium in each well. After 24 hours incubation, cells on the bottom side of the chamber membrane were fixed, stained with crystal violet, and photographed.

\section{Statistics}

The SPSS 15.0 software package (SPSS Inc, Chicago, IL, USA) was used for statistical analysis. Correlations between CHD5 expression and clinicopathological variables were evaluated by Chi-square $\left(\chi^{2}\right)$ test. Progressionfree survival (PFS) and overall survival (OS) rates were estimated by the Kaplan-Meier analysis. The Cox proportional hazard regression analysis was performed for the identification of relevant prognostic factors. For tumorigenesis experiments, tumor sizes or weights between two groups were analyzed using the Student's $t$ test. The statistical analysis was two-sided and $P$-values less than 0.05 were considered as statistically significant.

\section{Results}

\section{Mutation and copy number changes of CHD5 in breast} cancer

Sequencing the coding exons and adjacent splicing junctions of CHD5 in 38 primary tumors and 17 cell lines of breast cancer identified only one heterozygous frameshift mutation (3215delG) in the MDA-MB-231 cell line. A novel single nucleotide polymorphism (SNP) $(470 \mathrm{C}>\mathrm{T}$, Thr157Met) at the N-terminal region of CHD5 was detected in two tissue samples. In addition, eight known SNPs (previously reported in the SNP database) were detected in the primary tumors and/or cell lines. All sequence alterations, including known SNPs identified in this study, are summarized in Table 1.

Changes in CHD5's copy number were determined in 29 breast cancer cell lines and 15 paired breast cancer tissues by real-time PCR with a pool of normal human genomic DNA as the control for normal genome. Whereas no homozygous deletion was detected, 5 of the 29 (17\%) cell lines and 3 of the $15(20 \%)$ primary tumors showed a deletion in one to the two CHD5 copies. In addition, 5 of the 29 (17\%) cancer cell lines had an increased copy number (Figure 1). 
Table 1 Mutation and single nucleotide polymorphisms (SNPs) of CHD5 in 55 breast cancer samples

\begin{tabular}{ccccc}
\hline Exon & $\begin{array}{c}\text { Sequence } \\
\text { alteration }\end{array}$ & $\begin{array}{c}\text { Amino acid } \\
\text { alteration }\end{array}$ & \multicolumn{2}{c}{ Allele frequency } \\
\cline { 4 - 5 } & & & Cell lines & Tissues \\
\hline $\begin{array}{c}\text { Mutation } \\
21\end{array}$ & & & & \\
SNPS & & & $1 / 34$ & $0 / 76$ \\
$4^{*}$ & C570T & Thr157Met & $0 / 34$ & $3 / 76$ \\
4 & G529C & Leu & $8 / 34$ & $0 / 76$ \\
7 & C1003T & Phe & $15 / 34$ & $55 / 76$ \\
8 & A1204G & Val & $16 / 34$ & $55 / 76$ \\
12 & C1957T & Tyr & $3 / 34$ & $2 / 76$ \\
15 & C2479T & Asn & $0 / 34$ & $23 / 76$ \\
16 & T2593C & Ile & $11 / 34$ & $46 / 76$ \\
22 & G3436A & Ala & $0 / 34$ & $27 / 76$ \\
31 & T4715C & Ser1539Pro & $26 / 34$ & $0 / 76$ \\
\hline
\end{tabular}

Notes: 17 cell lines and 38 primary tumors of breast cancer were used. * indicates the novel SNP identified in this study. The rest of the SNPs have been reported in the SNP database (dbSNPs).

\section{Down-regulation of $\mathrm{CHD} 5$ in breast cancer}

CHD5 mRNA expression was determined in 32 cell lines and 58 primary tumors of breast cancer by real time PCR. Compared to HMEC, 20 of 32 cancer cell lines (62.5\%) showed reduced expression of $\mathrm{CHD} 5$ by at least $50 \%$, and 17 (53.1\%) had an reduction by at least $75 \%$. While six cell lines $(18.8 \%)$ did not have obvious expression changes, the remaining six cell lines (18.8\%) showed an increased expression of CHD5 by at least one fold (Figure 2A). CHD5 protein expression was confirmed in six breast cancer cell lines and HMEC cells by Western blotting. Consistent with real time PCR results in cell lines, CHD5 protein was strongly expressed in T-47D and HMEC, moderately expressed in BT549 and MCF-7, but not detectable in MDA-MB-361, MDA-MB-231 and Hs 578T (Figure 2B). All six, except the BT549 cell line, had a normal CHD5 copy number.

Compared to matched adjacent noncancerous tissues, 37 of 58 primary tumors $(63.8 \%)$ showed a reduced CHD5 mRNA expression by at least 50\%, 17 (29.3\%) had little change, and $4(6.9 \%)$ had an increased CHD5 expression. In 20 of the 58 (34.5\%) tumors, CHD5 was down-regulated by at least $75 \%$. Representative results from 11 paired samples are shown in Figure 2C. Statistical analysis demonstrated that CHD5 mRNA expression was significantly reduced in breast tumors compared to their matched normal tissues (independent $t$-test, $P<$ 0.05, Figure 2D). Furthermore, reduced CHD5 mRNA expression significantly correlated with lymph node metastasis (Mann-Whitney $U$ test, $P<0.05$ ), but not with age at diagnosis or the status of p53, ER, PR and HER2 (Additional file 1 Table S1).
CHD5 protein expression was examined in 289 formalin-fixed paraffin-embedded tumors and 20 normal breast tissues by IHC. We first examined the specificity of the CHD5 antibody in IHC staining (Figure 3A). CHD5 protein was positively identified in the nucleus of all 20 normal tissues (Figure 3B, Additional file 1 Table S2). In the breast cancer tissues, while 145 (50.2\%) tumors showed various levels of CHD5 protein expression, 144 of them (49.8\%) showed no obvious CHD5 expression (Figure 3DG, Additional file 1 Table S2). Statistical analysis indicated that lack of CHD5 expression significantly corrected with higher histological grade $(P=0.01)$, more HER2 positive tumors $(P<0.001)$, and less ER- $(P=0.009)$ or PR-positive $(P=0.001)$ tumors (Table 2$)$. According to molecular classification of breast cancer, more CHD5-positive breast cancers belonged to the luminal A subtype (ER+ and/or $\mathrm{PR}+$, HER2-), while more CHD5-negative tumors belonged to the luminal $\mathrm{B}(\mathrm{ER}+$ and/or $\mathrm{PR}+, \mathrm{HER} 2+)$, HER2 (ER-, PR-, HER2+), or the triple negative subtype (ER-, PR-, HER2-) $(P<0.001)$. No association was detected between CHD5 expression and patient age at diagnosis, tumor size, lymph node metastasis, or family history (Table 2).

Among the 289 patients, 242 received adjuvant chemotherapy, 132 received endocrine treatment, and 91 received radiation therapy. The average follow-up time was 61 months (ranged from 11 to 72 months). During the follow-up, 3 patients (1\%) developed local recurrence, 37 (12.8\%) developed distant metastasis, and 24 (8.3\%) died. Lack of CHD5 expression significantly correlated with distant metastasis $(P<0.001$, Chi squared analysis $)$ and death $(P=0.001)$ (Table 2$)$. Kaplan-Meier analysis indicated that patients with no CHD5 expression had significantly shorter progression-free survival (Figure 4A) and overall survival (Figure 4B). Moreover, multivariate Cox regression analysis indicates that lack of CHD5 expression is an independent prognostic factor (Additional file 1 Table S3).

\section{Promoter hypermethylation of CHD5 in breast cancer}

The methylation status of the CHD5 promoter region from -841 to -246 , which contains $58 \mathrm{CpG}$ sites and is frequently methylated in neuroblastoma cell lines [7], was determined in 9 breast cancer cell lines, 30 primary tumors, and 10 normal breast tissues. The majority of the $58 \mathrm{CpG}$ sites were methylated in breast cancer cell lines BT-20, MDAMB-231, ZR-75-30 and MDA-MB-175, while around half of the $58 \mathrm{CpG}$ sites were methylated in the MDA-MB-157 and BT-483 cancer cell lines (Figure 5A). In the remaining three cancer cell lines (BRF-71T, HCC38 and BT-549), CHD5 promoter methylation was detectable but to a much lower extent (Figure 5A). Strikingly, the four cell lines with the most extensive methylation (BT-20, MDA-MB-231, 


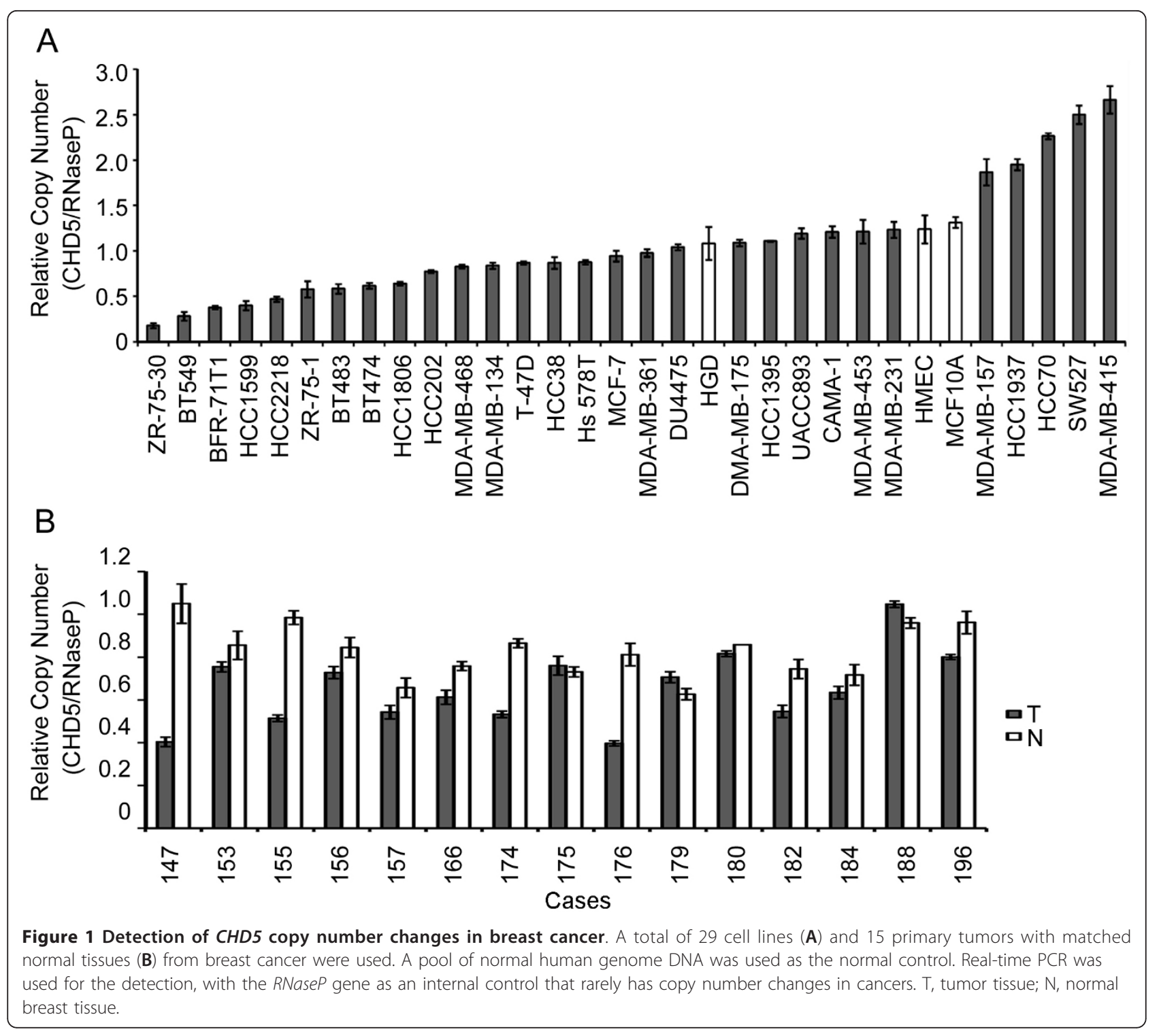

ZR-75-30 and MDA-MB-175) had barely detectable CHD5 mRNA expression, and only one of the four cell lines, ZR75-30, had a copy number loss at CHD5 (Additional file 1 Table S4), suggesting that promoter methylation is more often responsible for the down-regulation of $\mathrm{CHD} 5$ in some breast cancers.

To further determine whether promoter methylation is responsible for reduced CHD 5 mRNA expression in breast cancer, we treated MDA-MB-231 and Hs 578T cell lines, both of which had little CHD5 mRNA expression, with the 5-aza-2'-deoxycytidine (5-aza-CdR) demethylating agent ( 2 and $5 \mu \mathrm{M}$ ) for three days, and examined the effect of 5-aza-CdR on CHD5 expression. Real-time PCR assay showed that CHD5 mRNA level was doubled in MDA-MB-231 cells and tripled in Hs 578T cells after treatment with $2 \mu \mathrm{M} 5$-aza-CdR for three days, and was quadrupled in both cell lines after treatment with $5 \mu \mathrm{M} 5$-aza-CdR for three days (Figure 5B), which are consistent with a previous study [9]. Treatment with $5 \mu \mathrm{M} 5$-aza-CdR could even increase CHD5 expression at 12 and 24 hours in MDA-MB-231 cells (doubled at 12 hours and quadrupled at 24 hours) (Figure $5 \mathrm{C}$ ). As expected, sequencing of cloned bisulfite-treated DNA demonstrated a significantly decreased methylation level of CHD5 promoter in MDA-MB-231 cells treated with 5aza-CdR for 24 hours (Figure 5D).

In clinical specimens, the methylation level for each CpG site was averaged in 10 normal breast tissues and 30 primary tumors and plotted against the location of each CpG site (Figure 5E). The average methylation level per CpG site was 0.1 in the tumor samples, which was significantly higher than that in the normal samples (0.036) 

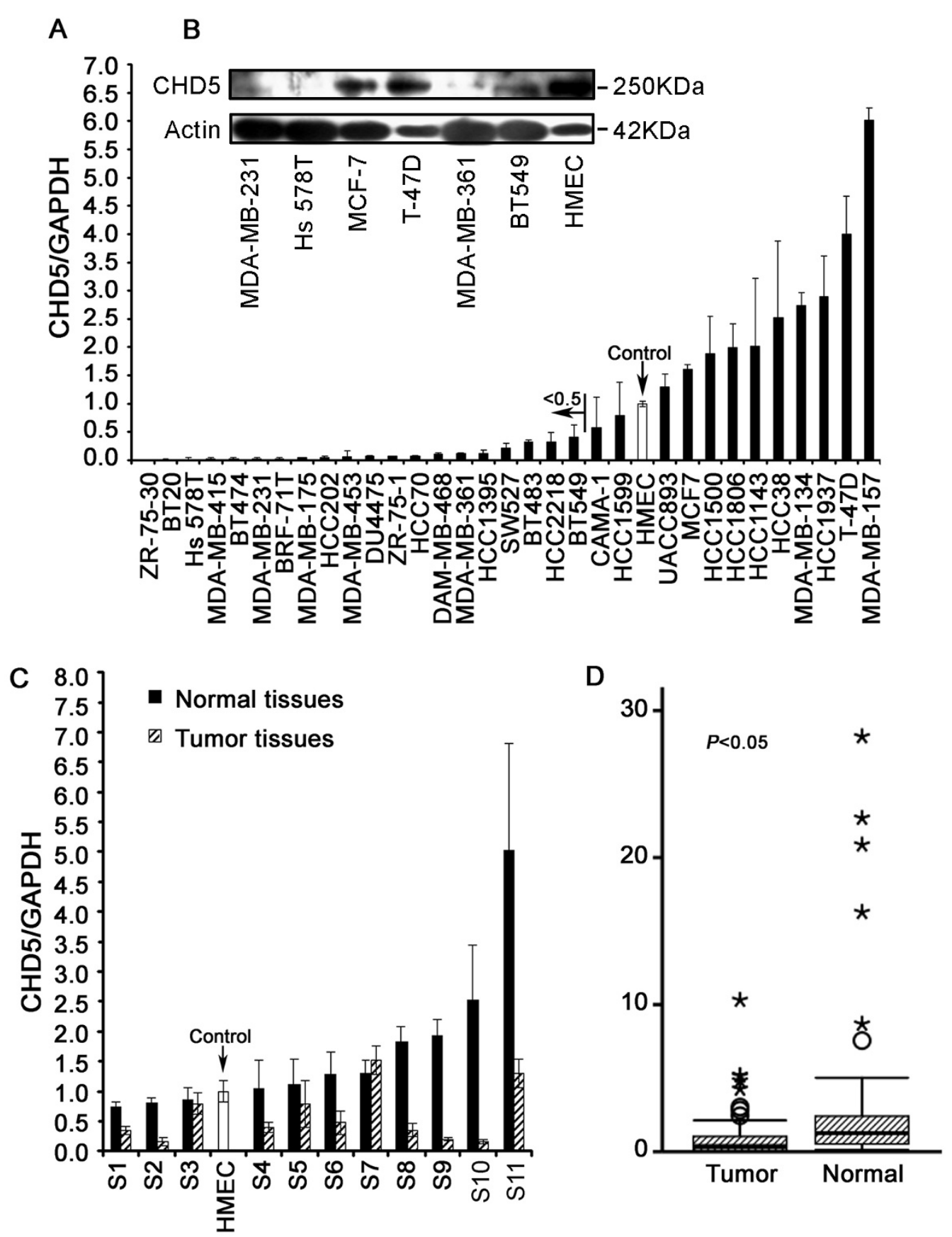

Figure 2 Down-regulation of CHD5 mRNA expression in breast cancer. (A) Expression of CHD5 mRNA in breast cancer cell lines and primary culture of human mammary epithelial cells (HMEC), as detected by real-time RT-PCR. GAPDH was used for normalization. The ratio CHD5/GAPDH in HMEC was defined as 1, and the ratio in other cell lines was adjusted accordingly. (B) Detection of CHD5 protein expression in six breast cancer cell lines and in HMEC cells by Western blotting. Actin was used as a loading control. (C) Representative results of CHD5 mRNA expression in breast cancer samples and matched normal tissues, as detected by real-time RT-PCR using HMEC as a positive control. The ratio of CHD5/GAPDH in HMEC was defined as 1, and that in other samples were normalized accordingly. (D) The distribution of CHD5 mRNA expression values in the tumor group $(n=58)$ versus that in the normal group $(n=58)$ are shown in the plot-box diagram. The box ranges from the $25^{\text {th }}$ to the $75^{\text {th }}$ percentile, and the bold line across the box indicates the median. The whiskers are 1.5 times of the quartile values. 


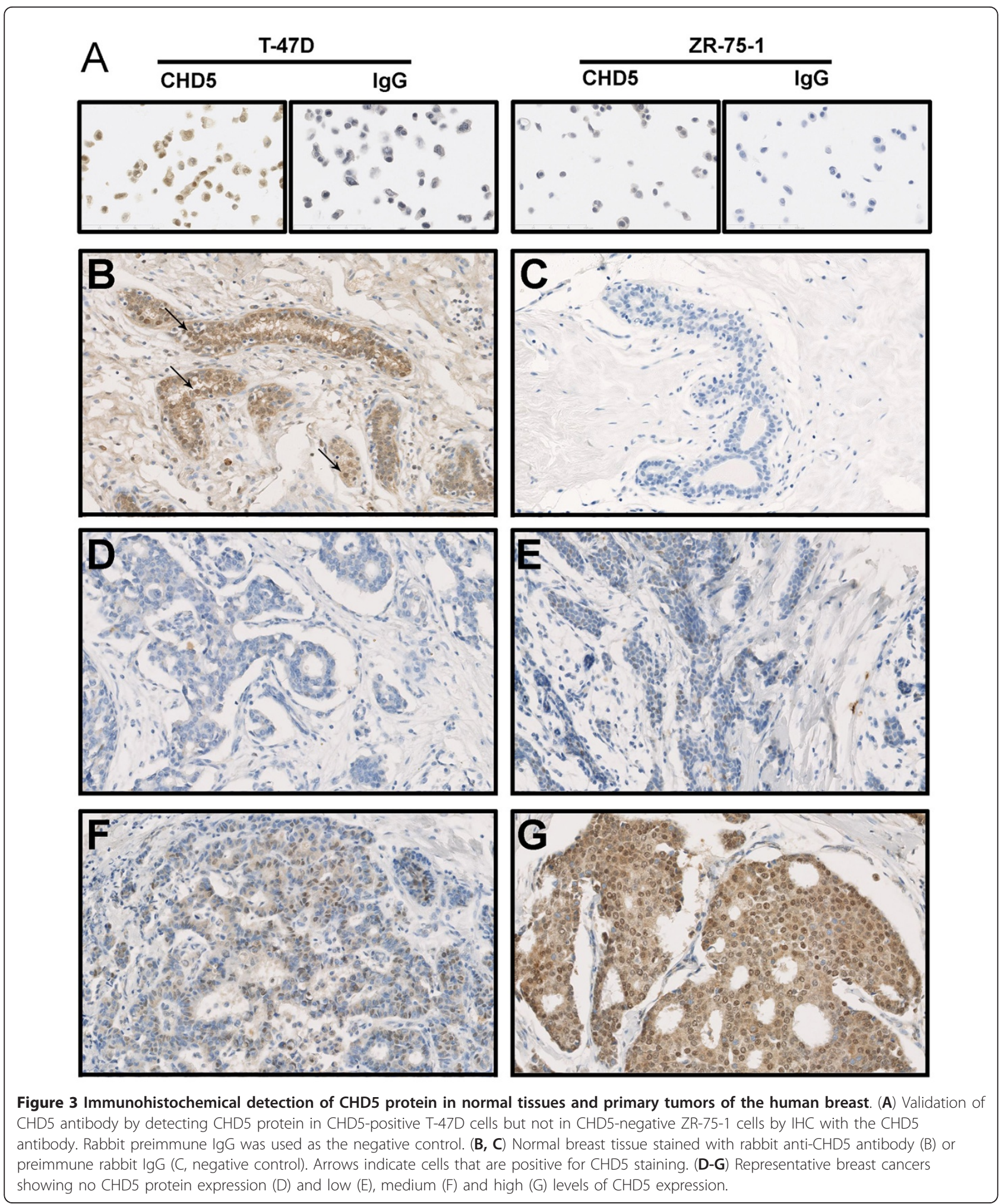

(independent $t$ - test, $P<0.001)$. The $\mathrm{CpG}$ sites between -626 and -399 were methylated more heavily in clinical tumors (Figure 5E).
Among the 30 primary tumors used in the methylation study, 19 had adjacent normal tissue and, therefore, were used for the detection of $\mathrm{CHD} 5$ expression by real 
Table 2 Correlation between CHD5 expression and clinicopathological parameters in breast cancer

\begin{tabular}{|c|c|c|c|c|}
\hline \multirow[t]{2}{*}{ Parameters } & \multicolumn{2}{|c|}{ CHD5 expression $(n)$} & \multirow[t]{2}{*}{ Total cases } & \multirow[t]{2}{*}{$P$-values } \\
\hline & - & + & & \\
\hline Age (years) & & & 289 & 0.590 \\
\hline$\leq 50$ & 67 & 62 & 129 & \\
\hline$>50$ & 78 & 82 & 160 & \\
\hline Tumor size & & & $288^{*}$ & 0.476 \\
\hline$\leq 2 \mathrm{~cm}$ & 29 & 34 & 63 & \\
\hline$>2 \mathrm{~cm}$ & 115 & 110 & 225 & \\
\hline Histological grade & & & $275^{*}$ & 0.010 \\
\hline 1 & 4 & 14 & 18 & \\
\hline$\|$ & 100 & 103 & 203 & \\
\hline III & 34 & 20 & 54 & \\
\hline pTNM stage & & & $284^{*}$ & 0.105 \\
\hline$|/| \mid$ & 99 & 111 & 210 & \\
\hline III/IV & 43 & 31 & 74 & \\
\hline LN metastasis & & & 289 & 0.215 \\
\hline- & 57 & 67 & 124 & \\
\hline+ & 88 & 77 & 165 & \\
\hline Estrogen receptor & & & 289 & 0.009 \\
\hline- & 66 & 44 & 110 & \\
\hline+ & 79 & 100 & 179 & \\
\hline Progesterone receptor & & & 289 & 0.001 \\
\hline- & 84 & 54 & 138 & \\
\hline+ & 61 & 90 & 151 & \\
\hline HER2 status & & & 289 & $<0.001$ \\
\hline- & 74 & 111 & 185 & \\
\hline+ & 71 & 33 & 104 & \\
\hline Molecular subtype & & & 289 & $<0.001$ \\
\hline luminal A & 54 & 95 & 149 & \\
\hline luminal B & 35 & 12 & 47 & \\
\hline HER2 & 37 & 20 & 57 & \\
\hline Triple negative & 19 & 17 & 36 & \\
\hline Family history & & & $264^{*}$ & 0.420 \\
\hline No & 105 & 98 & 203 & \\
\hline Yes & 28 & 33 & 61 & \\
\hline Distant metastasis & & & 289 & $<0.001$ \\
\hline No & 115 & 137 & 252 & \\
\hline Yes & 30 & 7 & 37 & \\
\hline Death & & & 289 & 0.001 \\
\hline No & 125 & 140 & 265 & \\
\hline Yes & 20 & 4 & 24 & \\
\hline
\end{tabular}

Notes: LN, lymph node; pTNM, pathological tumor node metastasis; *, analysis was limited to patients whose relevant information was available. Molecular subtypes were defined as below: luminal A, ER+ and/or PR+/HER2-; luminal B, $\mathrm{ER}+$ and/or PR+/HER2+; HER2+, ER-/PR-/HER2+; and triple negative, ER-/PR-/ HER2-. CHD5 expression is categorized into two groups: lack of expression "-" and expression at various levels " + ". $P$-values were determined by the Chisquare $\left(\chi^{2}\right)$ test.

time PCR. According to their average methylation levels, we divided the 19 tumors into two groups: one with lower levels of methylation $(0<$ average methylation level $<0.036,3$ cases) and the other with higher levels of methylation (average methylation level $>0.036,16$ cases). The same tumors were then divided into three groups according to the levels of CHD5 expression: low when CHD5 expression in a tumor was less than half of that in the matched normal tissue, moderate when the expression was more than half but less than two folds, and high when the expression was more than two folds. Notably, 12 of the 16 highly methylated tumors had low levels of CHD5 expression, while the 3 tumors with lower levels of methylation showed moderate or high CHD5 expression $(P=0.045$, Additional file 1 Table S5). These results suggest that hypermethylation of CHD5 promoter region is responsible for reduced CHD5 mRNA expression at least in some of the breast cancers.

\section{CHD5 suppresses the proliferation of breast cancer cells in vitro and in vivo}

We transfected MDA-MB-231 breast cancer cells, which have a truncation mutation of $\mathrm{CHD} 5$, with $\mathrm{CHD} 5$ expression plasmid or vector control. Expression of $\mathrm{CHD} 5$ was confirmed by Western blotting (Figure 6A). After selection with G418 for 12 and 16 days, expression of CHD5 significantly decreased colony-forming efficiency (independent $t$ test, $P<0.001$ ) (Figure 6B, C). We also examined cell cycle distribution of MDA-MB-231 cells after transfection and selection with G418. CHD5 expression increased the number of cells in G0/G1 phase while decreasing the number of cells in the $S$ and G2/M phases (Figure 6D, E).

Cell proliferation analysis was also conducted in $\mathrm{Hs}$ $578 \mathrm{~T}$ cells, in which CHD5-expressing plasmid or control plasmids were transfected, and the selection for positively transfected cells continued for two weeks. Compared to parental Hs 578T cells and those transfected with vector control or the plasmid expressing antisense-CHD5, proliferation activity of cells transfected with $\mathrm{CHD} 5$-expressing plasmid was significantly reduced (Figure 6F).

In the T-47D breast cancer cell line, which expresses a high level of CHD5, we knocked down CHD5 expression by RNAi, and unexpectedly detected a significant decrease in cell proliferation (Figure 6G).

The effect of CHD5 on cell proliferation was further tested in parental and derivative stable clones of MDA-MB-231 cells expressing varying levels of CHD5 (Figure 7A). Compared to parental MDA-MB-231 cells and two vector control clones (V1 and V2), clones or the population stably expressing CHD5 (S10, S14 and Smix) showed significantly slower cell proliferation (Figure 7B). We also examined parental MDA-MB-231 cells, the V1 vector control clone and the CHD5-expressing stable population (Smix) or clone (S14) for tumorigenesis in nude mice. While the control cell populations rapidly grew into tumors in nude mice, the CHD5expressing cells had significantly slower growth, as 
A

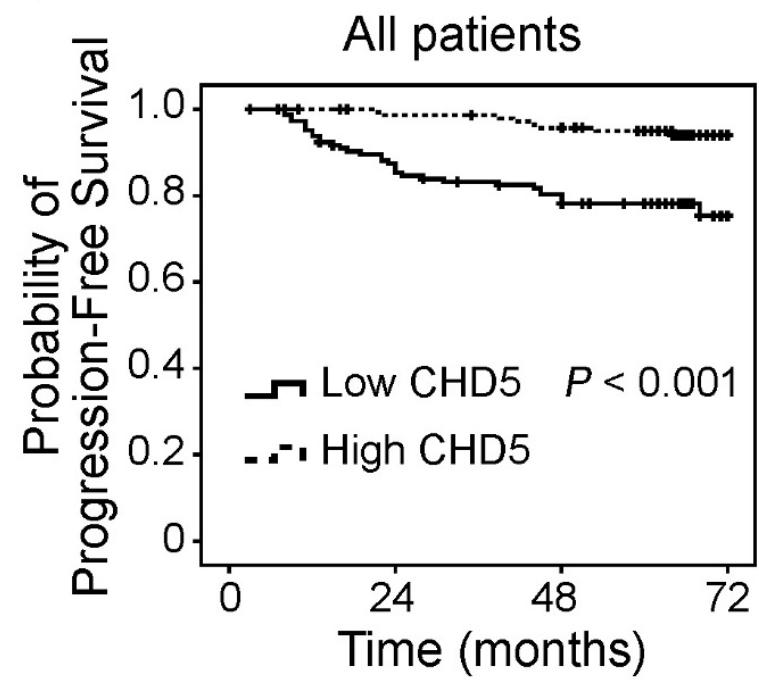

B

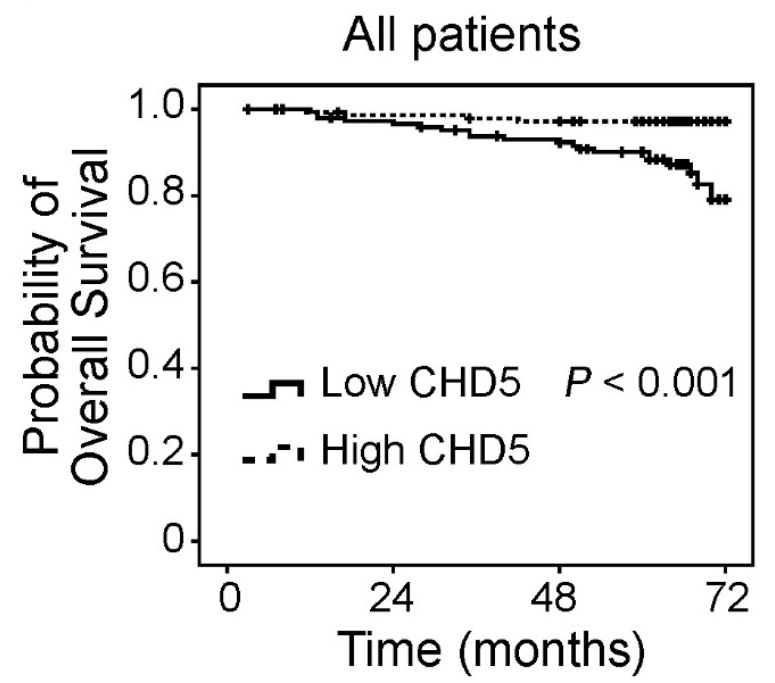

Figure 4 Lack of CHD5 protein expression is significantly associated with worse patient survival. Kaplan-Meier analysis of progression-free survival (A) and overall survival (B) in breast cancers with and without CHD5 protein expression. P-values were based on the log-rank test.

indicated by tumor volumes measured at Weeks 3 to 5 and tumor weights determined at Week 5 (Figure 7C, D). These results indicate that CHD5 suppresses breast cancer cell growth both in vitro and in vivo.

\section{CHD5 suppresses invasiveness of breast cancer cells in vitro}

The invasive ability of CHD5-expressing S10 and S14 clones were significantly impaired compared to parental MDA-MB-231 cells and vector control cells (Figure 8A). In the Hs 578T cell line, cell population stably transfected with CHD5 also showed an inhibition of invasion when compared to vector-transfected cell population (Figure 8B). Consistent with a decrease in invasiveness, protein expression of vimentin, a mesenchymal cell marker, was reduced in $\mathrm{S} 10$ and $\mathrm{S} 14$ cells (Figure 8C). In addition, protein expression of N-cadherin and ZEB1, two mesenchymal cell markers not detectable in MDA-MB-231 cells, were downregulated in CHD5-expression Hs 578T cells (Figure 8D). Furthermore, knockdown of CHD5 in T-47D cells reduced the expression of the epithelial marker E-cadherin and increased the expression of mesenchymal marker vimentin (Figure 8E), suggesting that CHD5 loss could induce EMT in CHD5-positive breast cancer cells. EMT makers N-cadherin, ZEB1 and ZEB2 were also examined in T-47D cells, but they were not detectable in this cell line. T-47D cells were not invasive in the invasion assay, and knockdown of CHD5 did not sufficiently induce invasiveness. These results suggest that in addition to modulating cell cycle, CHD5 also regulates cellular invasion by suppressing EMT in breast cancer cells.

\section{Discussion}

Deletion of $1 p 36$ is common in a variety of cancers, including breast cancer, suggesting that there is an important tumor suppressor gene in this region whose inactivation drives tumorigenesis. By analyzing mouse models generated by chromosome engineering to obtain different dosages of genomic interval D4Mit190-51, which corresponds to human 1p36, Bagchi et al. demonstrated that CHD5 was the leading tumor suppressor gene in this interval [2]. CHD5 has also been identified as a candidate tumor suppressor gene in neuroblastoma [18]. In this study, we conducted a series of studies to examine whether CHD5 is a tumor suppressor gene in human breast cancer. Whereas one mutation, a truncation mutation in the MDA-MB-231 breast cancer cell line, was found in CHD5 among the samples examined, CHD5 had frequent genomic deletion and promoter methylation in both breast cancer cell lines and primary tumors. Furthermore, promoter methylation correlated with transcriptional down-regulation of $\mathrm{CHD} 5$ and demethylating treatment increased CHD5 expression. CHD5 protein expression was also significantly reduced in primary breast tumors, and lack of CHD5 expression correlated with higher tumor grade, local recurrence, distant metastasis and worse patient survival. Functionally, CHD5 inhibited the proliferation and invasion of MDA-MB-231 and Hs 578T cells in vitro and tumorigenesis of MDA-MB-231 cells in vivo (Figures 1, 2, 3, 4, $5,6,7,8)$. Taken together with previous findings that showed deletion of $1 p 36$ in breast tumors [19,20], our results suggest that $\mathrm{CHD} 5$ is a tumor suppressor gene 
A

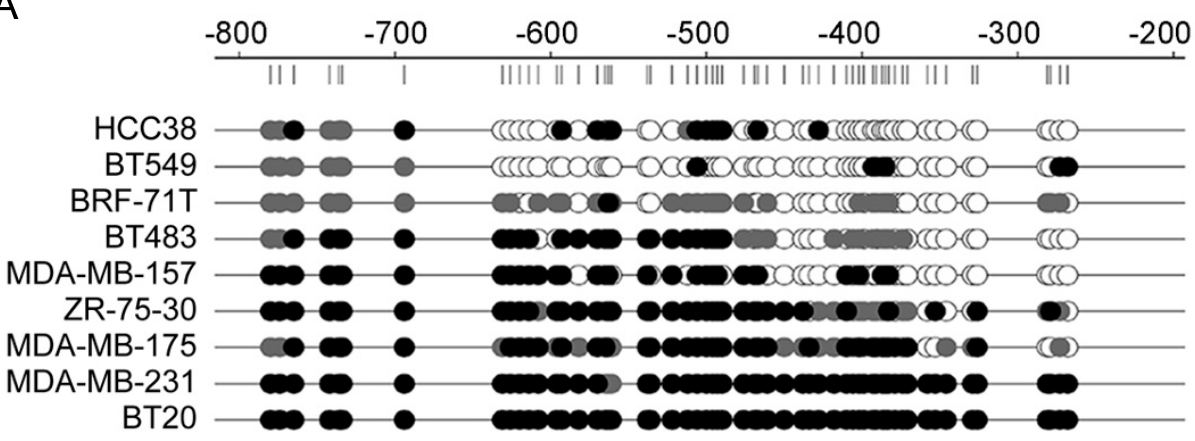

B

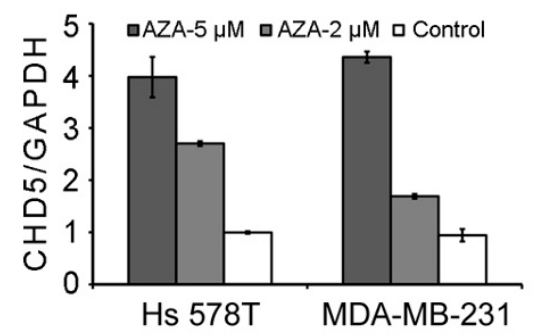

C

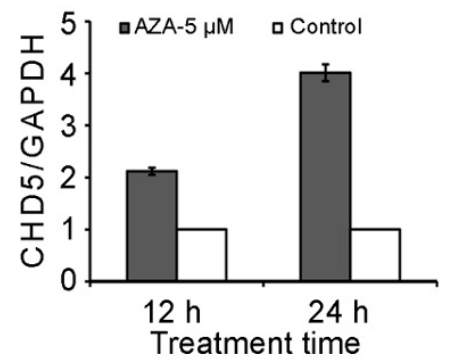

D

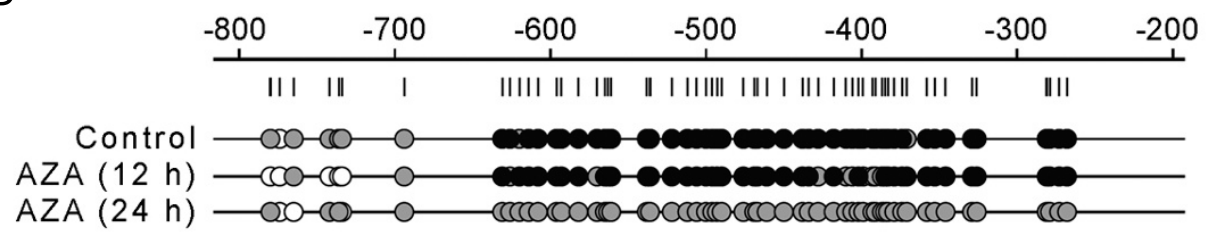

E

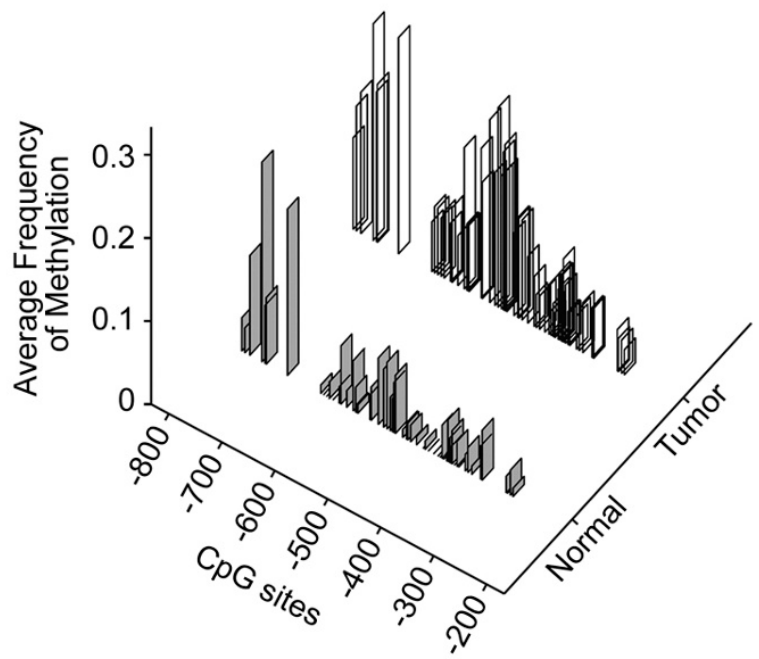

Figure 5 Methylation of CHD5 promoter region down-regulates CHD5 expression in breast cancer. (A) Methylation status of CHD5 promoter region in nine breast cancer cell lines as determined by bisulfite sequencing of cloned PCR products. The horizontal line at the top represents promoter DNA, whereas vertical lines under it indicate the relative locations of each CpG site. Methylation status of each $\mathrm{CpG}$ site is indicated by circles, and dark, gray and empty circles indicate high levels (methylation frequency $>50 \%$ ), moderate levels (methylation frequency $<50 \%$ ), and no (methylation frequency $=0$ ) methylation, respectively. $(\mathbf{B}, \mathbf{C})$ Detection of CHD5 mRNA levels by real time PCR in Hs 578T and MDA-MB-231 cell lines treated with 2 and $5 \mu$ M 5-aza-2'-deoxycytidine (AZA) for 3 days (B) or in MDA-MB-231 cells treated with $5 \mu$ M AZA for 12 and 24 hours (h) (C). GAPDH serves as an internal control. (D) Methylation levels of CHD5 promoter in MDA-MB-231 cells treated with AZA, as detected by bisulfite treatment and sequencing of five clones from each PCR product. Empty, gray and dark circles indicate zero, one to three and four or five clones, respectively, that are methylated. (E) Methylation levels of CHD5 promoter in breast tumors $(n=30)$ and normal breast tissues $(n=10)$. The frequency of methylation (y axis) at each CpG site ( $x$ axis) was the average frequency in either the tumor or the normal group. 


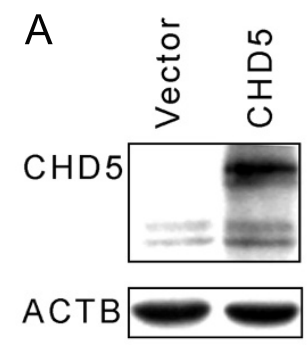

B

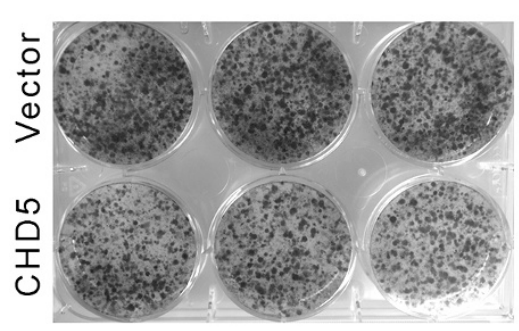

C

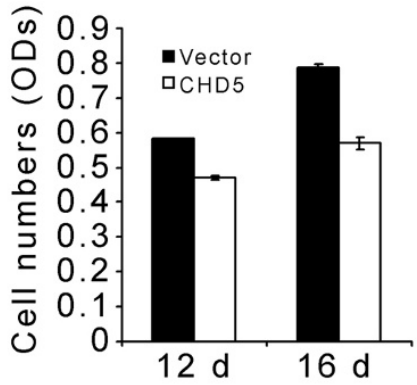

D
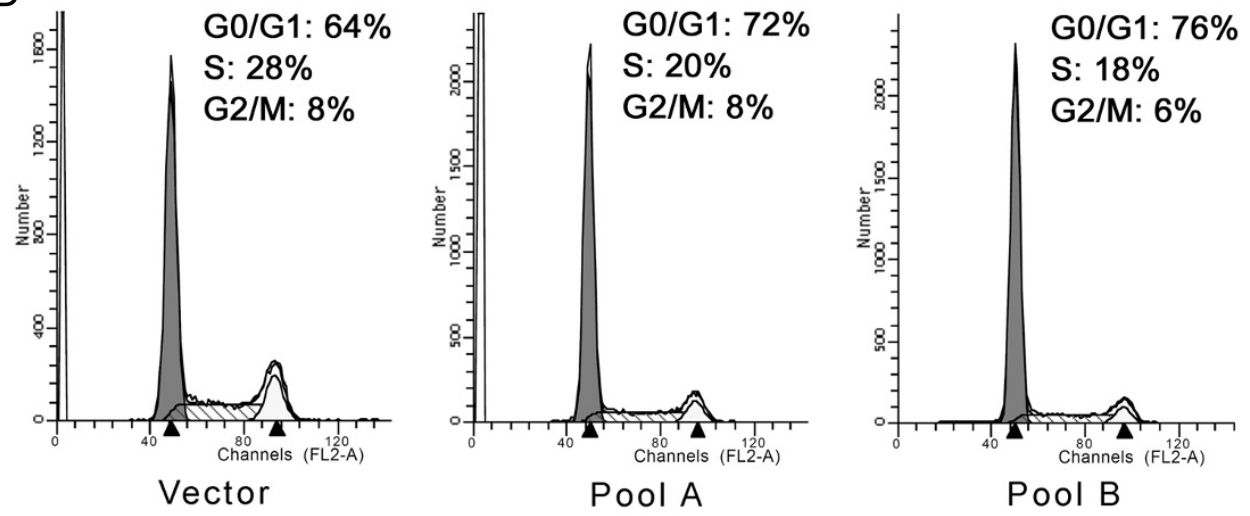

$\mathrm{E}$

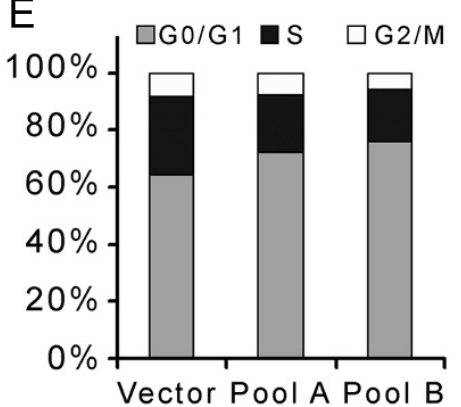

$\mathrm{F}$

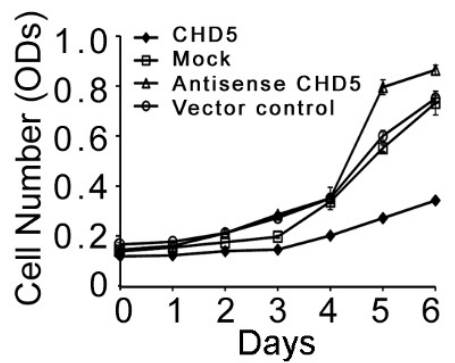

G

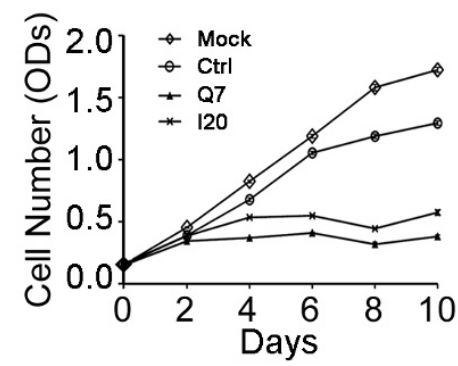

Figure 6 Effect of CHD5 on cell proliferation in breast cancer cell lines. (A) Confirmation of CHD5 expression in transfected MDA-MB-231 cells by Western blotting, with $\beta$-actin (ACTB) as a loading control. (B) Representative images of cells transfected with CHD5 or vector plasmid in six-well culture plates at 12 days of G418 selection. (C) Ectopic expression of CHD5 in MDA-MB-231 cells decreased colony formation efficiency at both 12 and 16 days of G418 selection, as detected by SRB staining. The numbers of cells are indicated by optical densities. (D, E) Ectopic expression of CHD5 increased the number of cells in the G0/G1 phase but decreased the number of cells in the $S$ phase of the cell cycle, as determined by flow cytometer. Transfected cells were selected by G418, and pools A and B were a mixture of transfected MDA-MB-231 cells from two independent transfection and selection experiments. (F) Ectopic expression of CHD5 inhibits cell proliferation in Hs 578T cells, as measured by SRB staining assay. Parental cells without plasmid transfection (mock) and cells transfected with empty vector (vector control) and antisense CHD5 were used as negative controls. (G) Knockdown of CHD5 expression by siRNAs (Q7 and 120) inhibits the proliferation of T-47D cells as compared to parental cells (Mock) or siRNA control (Ctrl).

whose inactivation by mutation, chromosomal deletion or promoter methylation-mediated transcriptional down-regulation plays a role in the development and progression of breast cancer.

We noticed that in the T-47D breast cancer cell line, which expresses a higher level of CHD5, RNAi-mediated knockdown of CHD5 did not increase cell proliferation. Unexpectedly, CHD5 knockdown decreased cell proliferation. While the reason for this unexpected finding remains to be determined, one possibility is that $\mathrm{T}$ 47D cells have acquired molecular alterations that have reversed the function of CHD5 from a proliferation suppressor to a proliferation enhancer. Such a functional reverse has been shown previously for some molecules. For example, TGF- $\beta$ is a potent tumor suppressor in early stage tumorigenesis but becomes a promoter in 


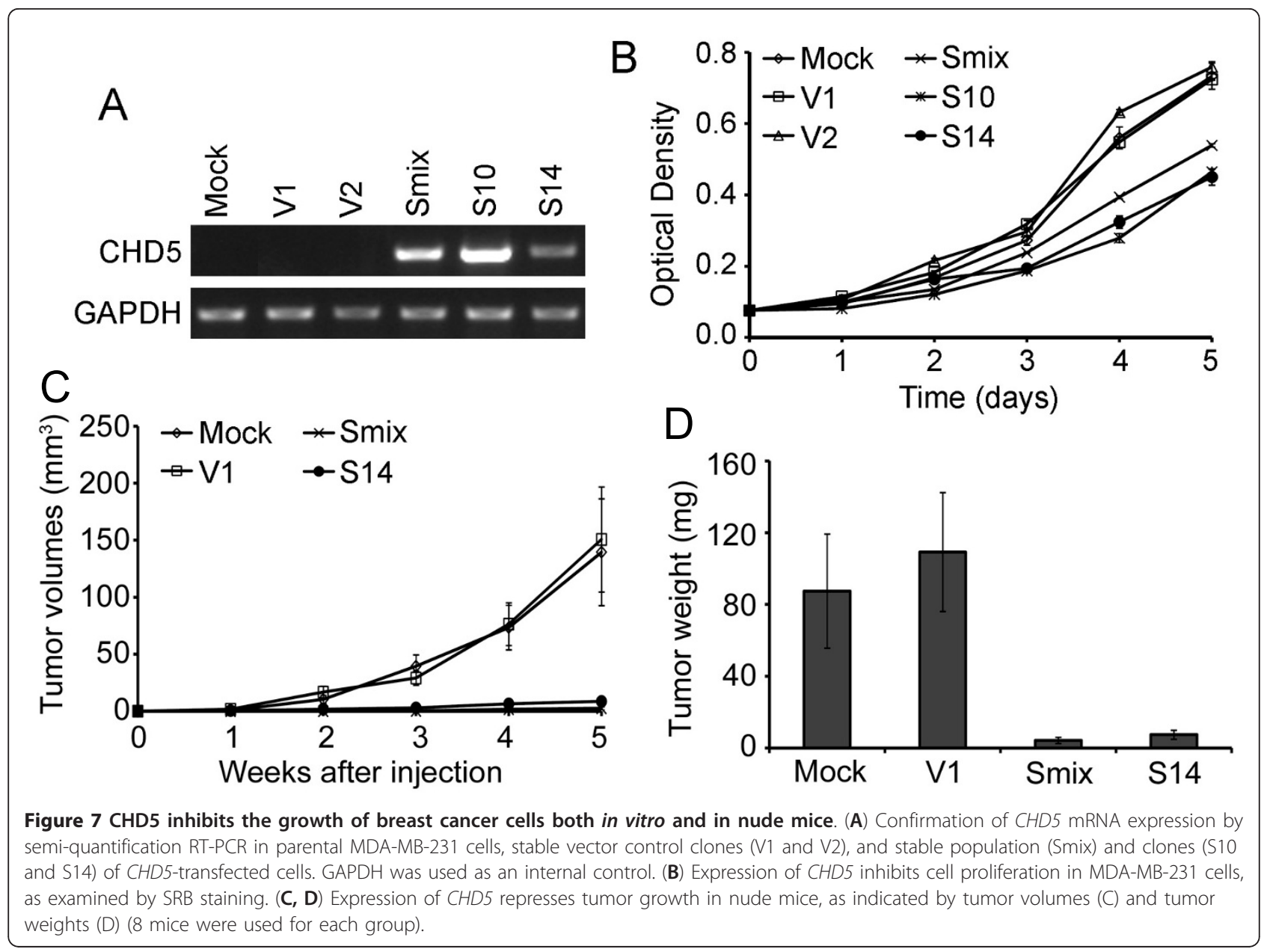

late stage tumor progression [21]; and deacetylation converts KLF5 from an anti-proliferative factor to a proproliferative in epithelial cells [22].

A tumor-specific function-altering mutation is a wellestablished indicator for tumor suppressor genes. In the original study that identified 122 genes with somatic mutations in breast cancer through large-scale DNA sequencing, two of the 11 (18\%) primary breast cancers had a heterozygous missense mutation in CHD5 (133G > A, V45M; 1999A > G, R667G) [12]. In our study, none of the 38 primary tumors had somatic mutations in CHD5, while one of the 17 breast cancer cell lines examined had a frame shift mutation. Our results are consistent with another report in which no mutations were detected in 60 breast cancer samples while three mutations were identified in 123 ovarian cancer samples [11], indicating that, although mutation of $C H D 5$ could occur in breast cancer, its frequency is rather low in primary tumors.

Among the SNPs detected in this study, some occurred frequently in cell lines but were not detected in primary tumors, including G529C (8/34 alleles or $24 \%$ ) and $\mathrm{T} 4715 \mathrm{C}(76 \%)$; others occurred frequently in the primary tumors but were not detected in any of the cell lines, including C2479T (30\%) and G3436A (36\%). These differences could be caused by differences in the ethnic background of patients whose primary tumors were used (Chinese) and patients from whom the cell lines were derived (non-Chinese). There is also a possibility that some of these SNPs contribute to successful establishment of breast cancer cell lines or even breast cancer progression, which remains to be determined.

Although somatic mutation of $C H D 5$ is rare, obvious down-regulation of $\mathrm{CHD} 5 \mathrm{mRNA}$ and protein was frequent in breast cancer cell lines and primary tumors. Hemizygous deletion and promoter methylation were also common and could be responsible for transcriptional down-regulation of CHD5 in breast cancer. In evaluating the role of promoter methylation in the down-regulation of $C H D 5$, we found that transcriptional down-regulation was significantly associated with promoter methylation and that demethylating treatment significantly increased CHD5 expression, indicting a role of methylation in decreasing CHD5 mRNA expression. These results are consistent with those from other types of tumors, such as 
A

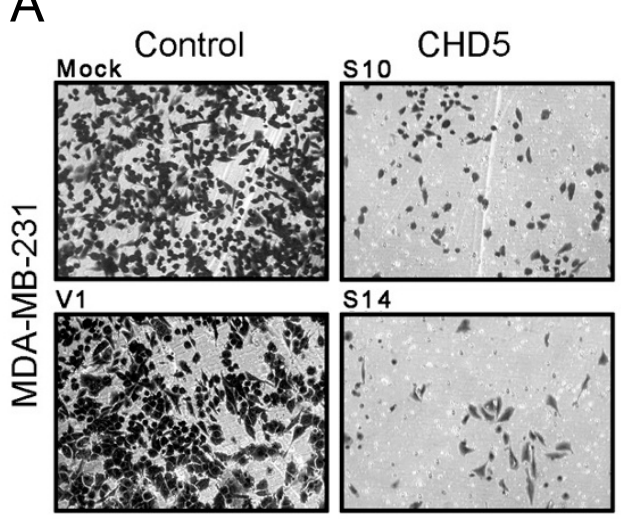

B

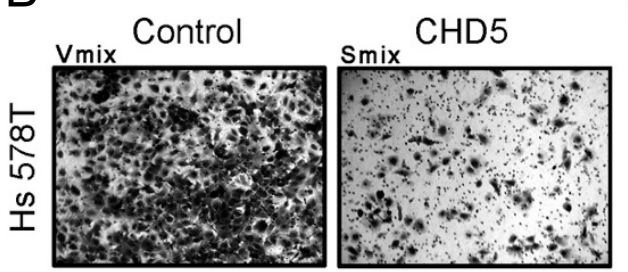

C

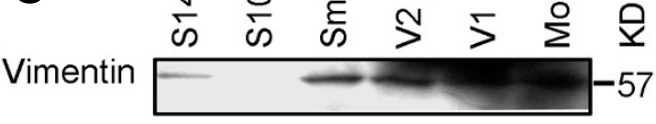

p21

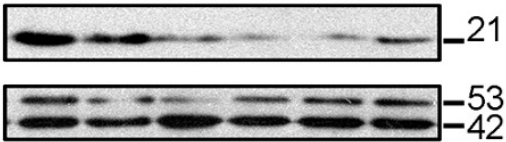

D

Actin
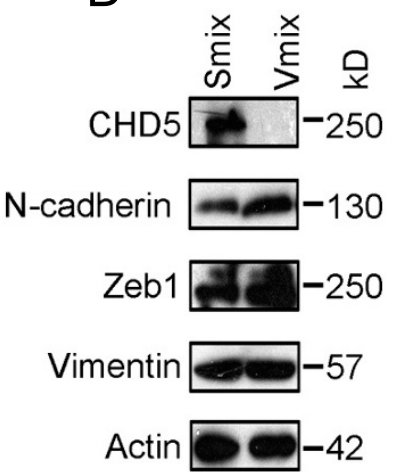
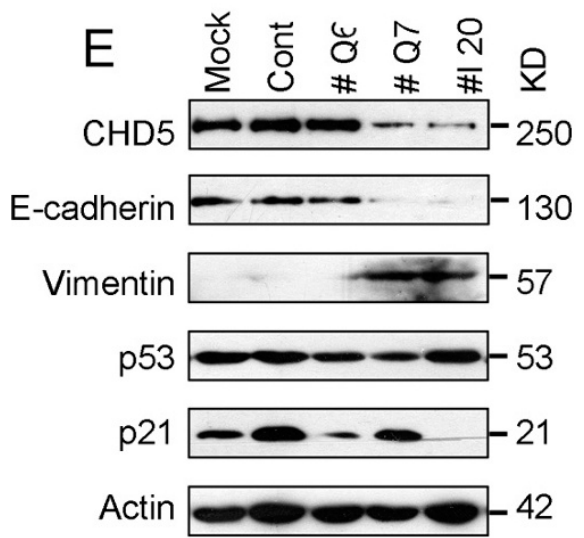

Figure 8 CHD5 suppresses the invasion and the expression of EMT markers in breast cancer cells. (A, B) Expression of CHD5 inhibits the invasion of MDA-MB-231 cells (A) and Hs 578T cells (B), as detected in the invasion assay. CHD5 or control is indicated at the top, and sample names are indicated at upper left. (C-E) Detection of different proteins by Western blotting, including vimentin, p21 and p53 in MDA-MB-231 cells without transfection (Mock) or transfected with CHD5 plasmid (Smix population and S10 and S14 clones) or control plasmid (V1 and V2 clones) (C); N-cadherin, ZEB1 and vimentin in Hs 578T cell population expressing CHD5 (Smix) or vector (Vmix) (D); and E-cadherin, vimentin, p53 and p21 in T-47D cells without transfection (Mock) or transfected with negative control siRNA (Cont) and CHD5 siRNAs (Q7 and I20) (E).

neuroblastoma and ovarian cancer, in which frequent promoter methylation and reduced RNA expression of CHD5 had also been detected [7-10]. Therefore, methylation-mediated silencing, which is a common mechanism for the inactivation of tumor suppressor genes, occurs at CHD5 in different types of human cancers including breast cancer.

Reduced CHD5 mRNA expression was significantly associated with lymph node metastasis, while reduced CHD5 protein expression significantly correlated to recurrence, distant metastasis, progression-free survival and overall survival in breast cancer. Multivariate Cox regression analysis indicates that lack of CHD5 expression is an independent prognostic factor. These results are consistent with a previous report where allelic loss at $1 p$ was correlated with lymph node metastasis in breast cancer [23] and that higher CHD5 expression was strongly associated with more favorable outcomes in neuroblastoma. Furthermore, the only breast cancer cell line harboring a truncated mutation at CHD5, MDA-MB-231, is highly metastatic. Therefore, it is possible that inactivation of CHD5 contributes to metastatic progression of breast cancer. Supporting this hypothesis, expression of CHD5 in the metastatic MDA-MB-231 and Hs 578T cells inhibited cellular invasiveness and down-regulated EMT markers.

Activation of the $\mathrm{p} 19^{\mathrm{Arf}} / \mathrm{p} 16^{\text {Ink4a }}$ locus by CHD5, which activates both $\mathrm{p} 19^{\mathrm{Arf}} / \mathrm{p} 53$ and $\mathrm{p} 16^{\text {Ink4a }} / \mathrm{Rb}$ signal axes, has been established as a mechanism for how CHD5 executes its tumor suppressor function. However, the three breast cancer cell lines used in our functional studies, MDAMB-231, Hs 578T and T-47D, harbor p53 mutations [24], and no significant change in p53 expression was detected in MDA-MB-231 cells expressing ectopic CHD5 or T-47D cells where CHD5 was knocked down (Figure $8 \mathrm{C}, \mathrm{E}$ ). $\mathrm{Rb}$ expression was not changed in CHD5-expressing MDA-MB-231 cells either (data not shown). In addition, whereas the expression of p21, a target gene of p53 involved in cell cycle arrest, was increased in CHD5expressing MDA-MB-231 cells (Figure 8C), its expression upon CHD5 knockdown in T-47D cells showed inconsistent changes, as p21 expression was decreased by one siRNA but not affected by another siRNA, although both siRNAs efficiently knocked down CHD5 (Figure 8E). We thus speculate that $\mathrm{CHD} 5$ suppresses breast carcinogenesis by a $\mathrm{p} 53$ - and Rb-independent mechanism. In fact, other mechanisms have been suggested in other types of tumors, as CHD5 mutation or methylation is associated 
with KRAS or BRAF mutation in ovarian cancer [11], and CHD5 expression correlates with MYCN amplification in neuroblastoma $[7,25]$.

\section{Conclusions}

In this manuscript, we found that promoter methylation, genomic deletion and down-regulation of CHD5 at both RNA and protein levels are common in breast cancer, and $C H D 5$ down-regulation was significantly associated with metastasis and worse patient survival in breast cancer. In addition, in the highly metastatic MDA-MB-231 breast cancer cell line, which harbors a truncating mutation, ectopic expression of CHD5 suppressed cell proliferation in vitro and tumorigenesis in nude mice by arresting the cell cycle, and inhibited cell invasion. Similar results were obtained in the Hs $578 \mathrm{~T}$ breast cancer cell line. These results suggest that CHD5 is an important tumor suppressor gene that could modulate the development and progression of human breast cancer.

\section{Additional material}

\section{Additional file 1: Table S1 through S5}

\begin{abstract}
Abbreviations
5-aza-CdR: 5-aza-2'-deoxycytidine; CHD: chromodomain helicase DNA binding protein; CpG: cytosine-phosphate-guanine; EMT: epithelialmesenchymal transition; ER: estrogen receptor alpha; GAPDH: glyceraldehyde 3-phosphate dehydrogenase; HER2: human epidermal growth factor receptor 2; HGD: human genomic DNA; HMEC: human mammary epithelial cells; IHC: immunohistochemistry; LN: Iymph node; M-MLV: Moloney murine leukemia virus; NuRD: nucleosome remodeling and histone deacetylation; OS: overall survival; PBS: phosphate-buffered saline; PFS: progression-free survival; PR: progesterone receptor; RT-PCR: reverse transcription polymerase chain reaction; SNP: single nucleotide polymorphism; SRB: sulforhodamine B.
\end{abstract}

\section{Acknowledgements}

This work was supported by grants from the National Natural Science Foundation of China (30870980, 30625032, and 30930038), Doctoral Fund of Ministry of Education of China (200800551032), the National Key Scientific Program of China (2007CB914802), and the Major Projects of National Science and Technology (2009ZX08009-151B).

\section{Author details}

'Department of Genetics and Cell Biology, Nankai University College of Life Sciences, 94 Weijin Road, Tianjin 300071, China. ²Department of Hematology and Medical Oncology, School of Medicine; Winship Cancer Institute, Emory University, 1365 Clifton Road, Atlanta, GA 30322, USA. ${ }^{3}$ Key Laboratory of Breast Cancer Research, Department of Breast Cancer Pathology and Research Laboratory, Cancer Hospital of Tianjin Medical University, Huan Hu Xi Road, Tianjin 300060, China.

\section{Authors' contributions}

XW carried out most molecular, genetic and functional experiments. She also extracted DNA and RNA samples from some tissue specimens and cell lines, and drafted the manuscript. WL read tissue slides and scored CHD5 $I H C$ staining with the guidance of LF. He also participated in animal experiments. XF conducted immunohistochemical staining of CHD5 in human tissues. DS conducted sequence data analysis and statistical analysis. LF participated in the mutation analysis of CHD5 in tumor samples and cell lines. ZZ and AL extracted DNA and RNA samples from some breast tissue specimens and cell lines. XS extracted DNA from some of the breast cancer cell lines and treated cell line DNA with sodium bisulfite for methylation analysis. LF is responsible for the collection and preparation of breast cancer tissues for analysis. ZZ and JTD designed the study, provided overall guidance and led the execution of all experiments. JTD is also responsible for the finalization of the manuscript. All authors read and approved the manuscript.

\section{Competing interests}

The authors declare that they have no competing interests.

Received: 12 November 2011 Revised: 18 January 2012

Accepted: 8 May 2012 Published: 8 May 2012

\section{References}

1. Bagchi A, Mills AA: The quest for the 1p36 tumor suppressor. Cancer Res 2008, 68:2551-2556.

2. Bagchi A, Papazoglu C, Wu Y, Capurso D, Brodt M, Francis D, Bredel M, Vogel H, Mills AA: CHD5 is a tumor suppressor at human 1p36. Cell 2007, 128:459-475.

3. Marfella CG, Imbalzano AN: The Chd family of chromatin remodelers. Mutat Res 2007, 618:30-40.

4. Woodage T, Basrai MA, Baxevanis AD, Hieter P, Collins FS: Characterization of the CHD family of proteins. Proc Natl Acad Sci USA 1997, 94:11472-11477.

5. Denslow SA, Wade PA: The human Mi-2/NuRD complex and gene regulation. Oncogene 2007, 26:5433-5438.

6. Thompson PM, Gotoh T, Kok M, White PS, Brodeur GM: CHD5, a new member of the chromodomain gene family, is preferentially expressed in the nervous system. Oncogene 2003, 22:1002-1011.

7. Fujita T, Igarashi J, Okawa ER, Gotoh T, Manne J, Kolla V, Kim J, Zhao H, Pawel BR, London WB, Maris JM, White PS, Brodeur GM: CHD5, a tumor suppressor gene deleted from 1p36.31 in neuroblastomas. J Nat/ Cancer Inst 2008, 100:940-949.

8. Wang X, Lau KK, So LK, Lam YW: CHD5 is down-regulated through promoter hypermethylation in gastric cancer. J Biomed Sci 2009, 16:95.

9. Mulero-Navarro S, Esteller M: Chromatin remodeling factor CHD5 is silenced by promoter $\mathrm{CpG}$ island hypermethylation in human cancer. Epigenetics 2008, 3:210-215.

10. Mokarram P, Kumar K, Brim H, Naghibalhossaini F, Saberi-firoozi M, Nouraie M, Green R, Lee E, Smoot DT, Ashktorab H: Distinct high-profile methylated genes in colorectal cancer. PLoS One 2009, 4:e7012.

11. Gorringe KL, Choong DY, Williams LH, Ramakrishna M, Sridhar A, Qiu W, Bearfoot JL, Campbell IG: Mutation and methylation analysis of the chromodomain-helicase-DNA binding 5 gene in ovarian cancer. Neoplasia 2008, 10:1253-1258.

12. Sjoblom T, Jones S, Wood LD, Parsons DW, Lin J, Barber TD, Mandelker D, Leary RJ, Ptak J, Silliman N, Szabo S, Buckhaults P, Farrell C, Meeh P, Markowitz SD, Willis J, Dawson D, Willson JK, Gazdar AF, Hartigan J, Wu L, Liu C, Parmigiani G, Park BH, Bachman KE, Papadopoulos N, Vogelstein B, Kinzler KW, Velculescu VE: The consensus coding sequences of human breast and colorectal cancers. Science 2006, 314:268-274.

13. Herman JG, Graff JR, Myohanen S, Nelkin BD, Baylin SB: Methylationspecific PCR: a novel PCR assay for methylation status of CpG islands. Proc Natl Acad Sci USA 1996, 93:9821-9826.

14. Climent J, Perez-Losada J, Quigley DA, Kim IJ, Delrosario R, Jen KY, Bosch A, Lluch A, Mao JH, Balmain A: Deletion of the PER3 gene on chromosome 1 p36 in recurrent ER-positive breast cancer. J Clin Oncol 2010, 28:3770-3778.

15. Chen C, Sun X, Ran Q, Wilkinson KD, Murphy TJ, Simons JW, Dong JT: Ubiquitin-proteasome degradation of KLF5 transcription factor in cancer and untransformed epithelial cells. Oncogene 2005, 24:3319-3327.

16. Chen L, Zhu Z, Sun X, Dong XY, Wei J, Gu F, Sun YL, Zhou J, Dong JT, Fu L: Down-regulation of tumor suppressor gene FEZ1/LZTS1 in breast carcinoma involves promoter methylation and associates with metastasis. Breast Cancer Res Treat 2009, 116:471-478.

17. Sun X, Frierson HF, Chen C, Li C, Ran Q, Otto KB, Cantarel BL, Vessella RL, Gao AC, Petros J, Miura Y, Simons JW, Dong JT: Frequent somatic mutations of the transcription factor ATBF1 in human prostate cancer. Nat Genet 2005, 37:407-412. 
18. Okawa ER, Gotoh T, Manne J, Igarashi J, Fujita T, Silverman KA, Xhao H, Mosse YP, White PS, Brodeur GM: Expression and sequence analysis of candidates for the 1 p36.31 tumor suppressor gene deleted in neuroblastomas. Oncogene 2008, 27:803-810.

19. Bieche I, Khodja A, Lidereau R: Deletion mapping of chromosomal region 1p32-pter in primary breast cancer. Genes Chromosomes Cancer 1999, 24:255-263.

20. Forozan F, Mahlamaki EH, Monni O, Chen Y, Veldman R, Jiang Y, Gooden GC, Ethier SP, Kallioniemi A, Kallioniemi OP: Comparative genomic hybridization analysis of 38 breast cancer cell lines: a basis for interpreting complementary DNA microarray data. Cancer Res 2000, 60:4519-4525.

21. Roberts $A B$, Wakefield $L M$ : The two faces of transforming growth factor beta in carcinogenesis. Proc Natl Acad Sci USA 2003, 100:8621-8623.

22. Guo P, Dong XY, Zhang X, Zhao KW, Sun X, Li Q, Dong JT: Pro-proliferative factor KLF5 becomes anti-proliferative in epithelial homeostasis upon signaling-mediated modification. J Biol Chem 2009, 284:6071-6078.

23. Tsukamoto K, Ito N, Yoshimoto M, Kasumi F, Akiyama F, Sakamoto G, Nakamura Y, Emi M: Allelic loss on chromosome $1 p$ is associated with progression and lymph node metastasis of primary breast carcinoma. Cancer 1998, 82:317-322.

24. Neve RM, Chin K, Fridlyand J, Yeh J, Baehner FL, Fevr T, Clark L, Bayani N, Coppe JP, Tong F, Speed T, Spellman PT, DeVries S, Lapuk A, Wang NJ, Kuo WL, Stilwell JL, Pinkel D, Albertson DG, Waldman FM, McCormick F, Dickson RB, Johnson MD, Lippman M, Ethier S, Gazdar A, Gray JW: A collection of breast cancer cell lines for the study of functionally distinct cancer subtypes. Cancer Cell 2006, 10:515-527.

25. Koyama H, Zhuang T, Light JE, Kolla V, Higashi M, McGrady PW, London WB, Brodeur GM: Mechanisms of CHD5 Inactivation in Neuroblastomas. Clin Cancer Res 2012, 18:1588-1597.

doi: $10.1186 / \mathrm{bcr} 3182$

Cite this article as: Wu et al: Chromodomain helicase DNA binding protein 5 plays a tumor suppressor role in human breast cancer. Breast Cancer Research 2012 14:R73.

\section{Submit your next manuscript to BioMed Central and take full advantage of:}

- Convenient online submission

- Thorough peer review

- No space constraints or color figure charges

- Immediate publication on acceptance

- Inclusion in PubMed, CAS, Scopus and Google Scholar

- Research which is freely available for redistribution

Submit your manuscript at www.biomedcentral.com/submit 